\title{
Brain damage and mortality in dogs following pulsatile and non-pulsatile blood flows in extracorporeal circulation
}

\author{
G. WRIGHT and J.M.SANDERSON \\ W. E. Dunn Unit of Cardiology, Biology Department, University of Keele, Staffordshire
}

In a series of 20 dog experiments, total cardiac bypass was followed by a high rate of mortality during the first 12 postoperative hours. Only five dogs survived for one week, but a further three dogs were perfuse-fixed after shorter periods of survival. All dogs developed pulmonary alveolar haemorrhages and seven of the eight perfuse-fixed brains exhibited brain damage. Diffuse nerve cell changes were found in the brains of dogs subjected to non-pulsatile blood flow. Focal brain lesions were found following both pulsatile and non-pulsatile blood flows. The lesions varied from staining pallor and rarefaction of the neuropil to total nerve cell loss and glial infiltration depending upon the duration of survival. When considered in conjunction with a previous series of experiments, these results show that the diffuse nerve cell changes associated with roller pump perfusions can be avoided by using a new pulsatile pump, but focal brain damage was not eliminated, and lung damage and mortality were not reduced.

It is well known that transient and permanent neurological disturbances follow open-heart surgery in human patients. A review of the scientific literature revealed several possible causative factors. The general view appears to be that, in addition to pre- and post-operative complications, the techniques of extracorporeal circulation currently employed cause some brain damage. The convention of using non-pulsatile blood flow for extracorporeal circulation was criticized by Sanderson, Wright, and Sims (1972b) who found diffuse nerve cell changes in the brains of dogs perfuse-fixed immediately following two or three hours of nonpulsatile extracorporeal circulation. This paper is a report of a similar series of experiments in which the animals were allowed to survive after total cardiac bypass.

\section{MATERIALS AND METHODS}

General anaesthesia was induced in 20 beagle and harrier dogs, $6 \cdot 8-17 \cdot 2 \mathrm{~kg}$ body weight, by the intravenous injection of $0.25-0.5 \mathrm{~g}$ of thiopentone sodium (Intraval) (Table I). Following endotracheal intubation, the dogs were artificially ventilated by a Palmer Ideal respirator delivering $200-400 \mathrm{ml} /$ stroke at 16 strokes/min, and light anaesthesia was maintained with a variable mixture of $0.0-2.0 \%$ halothane (Fluothane) in nitrous oxide and oxygen.

A modified Drew (1961) technique was used to establish an extracorporeal circulation, employing either occlusive roller pumps (DeBakey, 1934) or the Morton-Keele pulsatile pump (Sanderson et al., in preparation) with Harvard remote diaphragm heads (Harvard Apparatus Co. Inc.). The circuit tubing was $6.0 \mathrm{~mm}$ internal diameter (i.d.) polyvinyl chloride (PVC). The reservoirs were also made of PVC and each reservoir had a capacity of $300 \mathrm{ml}$. The heat exchanger consisted of four stainless steel tubes each $1.5 \mathrm{~m}$ in length and $6.0 \mathrm{~mm}$ i.d. mounted in a copper water jacket. The heat exchanger was placed in the

T A B LE I

EXPERIMENTAL DATA FOR EXTRACORPOREAL CIRCULATION EXPERIMENTS IN DOGS

\begin{tabular}{c|l|r|l|l}
\hline $\begin{array}{c}\text { Experiment } \\
\text { No.1 }\end{array}$ & $\begin{array}{c}\text { Type of } \\
\text { Perfusion }\end{array}$ & $\begin{array}{c}\text { Body } \\
\text { Weight } \\
\text { (kg) }\end{array}$ & Result & $\begin{array}{r}\text { Recovery } \\
\text { Duration }\end{array}$ \\
\hline $1 / 105$ & Pulsatile & $17 \cdot 2$ & Survived & 7 days \\
$2 / 156$ & Pulsatile & $9 \cdot 1$ & Survived & 8 days \\
$3 / 102$ & Pulsatile & $9 \cdot 0$ & Died & 2 hours \\
$4 / 130$ & Pulsatile & $12 \cdot 3$ & Died & 5 hours \\
$5 / 132$ & Pulsatile & $11 \cdot 3$ & Died & 3 hours \\
$6 / 145$ & Pulsatile & $10 \cdot 9$ & Died & 0 hours \\
$7 / 150$ & Pulsatile & $10 \cdot 8$ & Died & 0 hours \\
$8 / 154$ & Pulsatile & $9 \cdot 5$ & Died & 12 hours \\
$9 / 155$ & Pulsatile & $11 \cdot 8$ & Died & $0 \cdot 5$ hours \\
$10 / 157$ & Pulsatile & $10 \cdot 4$ & Died & 1 hour \\
$11 / 98$ & Non-pulsatile & $15 \cdot 4$ & Survived & 7 days \\
$12 / 117$ & Non-pulsatile & $15 \cdot 0$ & Survived & 7 days \\
$13 / 144$ & Non-pulsatile & $11 \cdot 7$ & Survived & 7 days \\
$14 / 119$ & Non-pulsatile & $6 \cdot 8$ & Terminated & 3 hours \\
$15 / 108$ & Non-pulsatile & $12 \cdot 7$ & Terminated & $7 \cdot 5$ hours \\
$16 / 86$ & Non-pulsatile & $10 \cdot 4$ & Terminated & 8 hours \\
$17 / 97$ & Non-pulsatile & $14 \cdot 5$ & Died & 12 hours \\
$18 / 142$ & Non-pulsatile & $9 \cdot 0$ & Died & 5 hours \\
$19 / 143$ & Non-pulsatile & $12 \cdot 2$ & Died & $4 \cdot 5$ hours \\
$20 / 158$ & Non-pulsatile & $8 \cdot 6$ & Died & 2 hours \\
\hline
\end{tabular}

1 The second figure denotes the Keele series 
left atrial drain instead of being in the delivery line from the pump. This translocation was introduced to reduce damping of the pulse delivered by the pulsatile pump.

All of the cannulae were made of stainless steel. The atria were drained through $6.0 \mathrm{~mm}$ i.d. fenestrated cannulae. The internal diameters of the arterial cannulae were 4.0 or $5.0 \mathrm{~mm}$ for the pulmonary artery, $2.5,3.0$ or $3.5 \mathrm{~mm}$ for the femoral artery, and $4.0,5.0$ or $6.0 \mathrm{~mm}$ for the proximal aorta, depending upon the diameter of the lumen of the artery.

The extracorporeal circuit was primed with 1,300 $\mathrm{ml}$ dog blood; $10 \mathrm{ml} \mathrm{10 \%} \mathrm{low} \mathrm{molecular} \mathrm{weight} \mathrm{dex-}$ tran in $0.9 \%$ sodium chloride (Rheomacrodex) and $4 \mathrm{ml} 10 \%$ mannitol $/ \mathrm{kg}$ of body weight; plus $4 \mathrm{ml}$ $20 \%$ sodium bicarbonate, one million international units soluble penicillin, 2,500 international units heparin, and $3 \mathrm{ml} 20 \%$ calcium chloride $/ 500 \mathrm{ml}$ priming fluid.

Using sterile surgical techniques, a median sternotomy was performed to permit cannulation of the right and left atria and the pulmonary artery. For non-pulsatile flow, the aorta was retrogradely perfused through the left femoral artery. The proximal aorta was cannulated for pulsatile flow because earlier experiments had shown that the pulse is severely damped when perfusing through narrow cannulae such as those necessary for femoral artery inputs.

A standard frequency of 100 strokes/min was employed for pulsatile experiments. Pulsatile blood flow rates were measured by a Medelec electromagnetic flowmeter (Medical and Laboratory Instrumentation Ltd.) placed in the systemic arterial line. Non-pulsatile blood flow rates were measured by the frequency of roller revolutions. Both measurements were calibrated with saline before starting the perfusions. Maximal blood flows were limited by venous returns to $56-110 \mathrm{ml} / \mathrm{kg}$ of body weight per minute. When flows had been stabilized, the heart was fibrillated with direct current shocks and maintained in a state of ventricular fibrillation for one hour of perfusion with the oesophageal temperature at $29 \cdot 0-31 \cdot 0^{\circ} \mathrm{C}$. The circulating blood was then warmed for 20 minutes to raise the oesophageal temperature to $30.4-38.0^{\circ} \mathrm{C}$ before defibrillation.

During perfusion, the fluid levels in the reservoirs were kept constant by homologous blood infusions. One femoral artery was exposed and a number 6 French side-eye pressure catheter was passed up to the lower abdominal aorta for the measurement of arterial blood pressure. The catheter was connected by stiff polythene tubing to a $0-300 \mathrm{mmHg}$ strain gauge pressure transducer with inputs to an ElemaSchönander Mingograph multichannel pen-recorder and an Airmec display oscilloscope. Heparin (300 international units $/ \mathrm{kg}$ of body weight) was administered to the animal before the introduction of the femoral artery catheter. Venous blood pressure was measured by a saline manometer connected to a 17-gauge intravenous cannula passing through the skin into the right cephalic vein. Both arterial and venous blood pressures were recorded at 10-minute intervals before, during, and for one hour after each perfusion. The oesophageal temperature and electrocardiograph were continuously monitored. Blood samples were obtained from a femoral artery before and after perfusion and from a two-way sampling tap in the left atrial drain during perfusion for estimates of arterial blood carbon dioxide tension $\left(\mathrm{PACO}_{2}\right), \mathrm{pH}$, standard bicarbonate and base excess using Astrup micro-equipment. Base deficits were corrected with sodium bicarbonate.

After defibrillating the heart, the cannulae were removed and protamine sulphate was administered, the amount required to neutralize the remaining heparin being determined by titration (Hurt, Perkins, Osborn, and Gerbode, 1956). The surgical incisions were repaired, chest drainage tubes were inserted, and an intravenous blood drip was maintained to replace the blood lost. Ampicillin and cloxacillin, $500 \mathrm{mg}$ of each, were given by intramuscular injection and the animals were allowed to survive for seven or eight days if possible before whole-body perfusion-fixation and subsequent histological processing by the technique of Wright and Sanderson (1970). Five dogs were perfuse-fixed as controls.

Thirteen representative tissue blocks were obtained from each brain. Pieces of left and right atria, left and right ventricles, aorta, lung, liver, kidney, and jejunum were selected and all of the tissue blocks were processed and doubly embedded in celloidin and paraffin wax. Sections of the brain were stained with Ehrlich's haematoxylin and eosin (H-E), Weigert's haematoxylin and van Gieson (H-VG), haemalum and periodic acidSchiff (H-PAS), luxol fast blue and cresyl fast violet (LFB-CFV), cresyl fast violet alone (CFV), and Mallory's phosphotungstic acid and haematoxylin (PTAH). Frozen sections were stained for fat with a saturated solution of Sudan III plus IV. Sections of other organs were stained with H-E.

\section{RESULTS}

The arterial blood pressure waveforms generated by the pulsatile and non-pulsatile pumps have been described previously (Sanderson et al., 1972 $a$ and b). The essential feature of the MortonKeele pulsatile pump is the rapid upstroke on the phasic pressure wave resembling that produced by the heart.

MORTALITY Of the 10 attempts to obtain one week of recovery after pulsatile perfusion, only two reached a successful conclusion (Table I). Of the 10 attempts to obtain one week of recovery after non-pulsatile perfusion, three dogs survived for one week, three dogs were perfuse-fixed after shorter periods of survival because of poor prognoses, and four dogs died during the early recovery period. 
Fatal technical errors were committed in three of the pulsatile experiments (nos. 7/150, 9/155, and $10 / 157)$. The positioning of the aortic cannula for pulsatile perfusions is critical. The requirement of a wide bore cannula to avoid pulse damping adds to the technical difficulty of cannulating a narrow aorta and introduces the danger of inadequate coronary perfusion due to obstruction of the proximal aorta by the cannula. In experiment $7 / 150$, this resulted in acute myocardial ischaemia and defibrillation failure at the end of the perfusion. Withdrawal of the aortic cannula into the left ventricle resulted in distension of the left heart, severe pulmonary oedema, and bronchial haemorrhage at the end of the perfusion in experiment 9/155. Leakback of blood from the pulmonary artery cannula into the right ventricle caused right heart distension and the formation of bloodstained bronchial fluid leading to hypoxia and death in experiment 10/157. Pump failure caused a further death in the pulsatile series (experiment $6 / 145$ ). No fatal technical errors or accidents were recognized in the non-pulsatile series.

When animals died following apparently uneventful perfusions, the developing pattern of morbidity was fairly consistent. The morbid signs were a failure to recover consciousness, prolonged postoperative bleeding into the thorax, and sudden cardiac arrest following several hours of satisfactory progress (Table II). These three morbid signs were not mutually exclusive.

Twelve animals failed to recover consciousness within the first two hours following cardiac bypass. Of these, two animals had received pulsatile and 10 had received non-pulsatile perfusions. All of the four animals that recovered consciousness within the first two postoperative hours had received pulsatile perfusions.

Persistent postoperative bleeding occurred in eight animals. Only two of the animals in this

T A B L E II

MORBID SIGNS FOLLOWING PULSATILE AND NONPULSATILE EXTRACORPOREAL CIRCULATION IN DOGS

\begin{tabular}{c|c|c|c|c}
\hline & $\begin{array}{c}\text { Technical } \\
\text { Faults }\end{array}$ & $\begin{array}{c}\text { Prolonged } \\
\text { Uncon- } \\
\text { sciousness }\end{array}$ & $\begin{array}{c}\text { Post- } \\
\text { operative } \\
\text { Bleeding }\end{array}$ & $\begin{array}{c}\text { Sudden } \\
\text { Cardiac } \\
\text { Arrest }\end{array}$ \\
\hline \begin{tabular}{c|c} 
Pulsatile \\
Survived \\
Terminated \\
Died
\end{tabular} & 0 & 0 & 1 & 0 \\
$\begin{array}{c}\text { Non-pulsatile } \\
\text { Survived } \\
\text { Terminated }\end{array}$ & 0 & 0 & 0 & 0 \\
$\quad$ Died & 0 & 2 & 3 & 2 \\
\hline Totals & 0 & 3 & 1 & 0 \\
\hline
\end{tabular}

group survived for one week (1/105 and 11/98). The volume of fluid drainage from the chest varied from 100 to $800 \mathrm{ml}$ during the first two hours after skin closure. This volume was always replaced as accurately as possible by the intravenous transfusion of homologous blood to maintain a constant effective blood volume as indicated by the maintenance of a normal central venous pressure. The duration of bleeding was from 30 minutes to 10 hours. Blood loss did not always determine survival or death. However, postoperative bleeding appears to have been a major factor in the early deaths of dogs $5 / 132,9 / 155$, and $10 /$ 157 (pulsatile), and of dogs $17 / 97$ and $18 / 142$ (non-pulsatile). It was responsible for the poor prognosis in dog 16/86 (non-pulsatile).

Sudden cardiac arrests terminated two of the pulsatile experiments $(5 / 132$ and $8 / 154)$ and one of the non-pulsatile experiments $(20 / 158)$.

It may be significant that the abdominal aorta blood pressures of the animals that died were lower than those of the survivors at all stages from the start of recording to the end of the perfusion (Fig. 1).

The necropsy findings were usually those commonly associated with cardiac failure. Splanchnic venous congestion was usually present and pulmonary thrombo-haemorrhages were found in 5 of the 12 dogs that died ( 3 pulsatile and 2 nonpulsatile). The organs of the perfuse-fixed animals

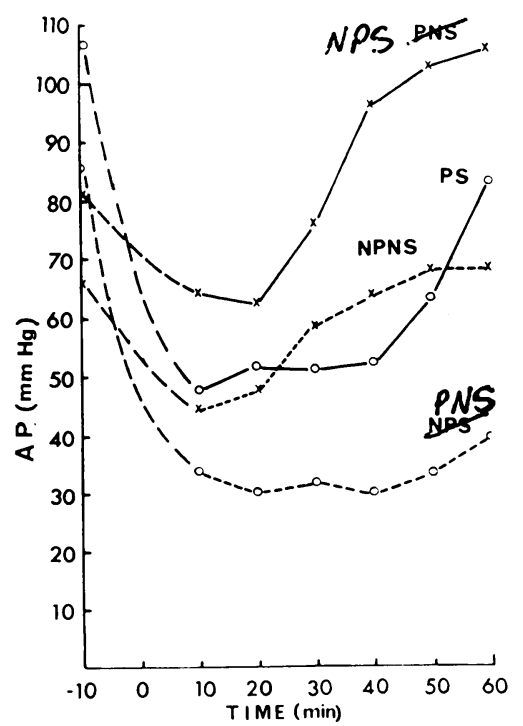

FIG. 1. Abdominal aorta blood pressure changes during pulsatile and non-pulsatile extracorporeal circulation. PS and NPS = pulsatile and non-pulsatile one-week survivors; $P N S$ and NPNS = pulsatile and non-pulsatile non-survivors 
were mostly normal. Moderate pleural and pericardial effusions were present in all of these animals. A recently formed thrombus occluded the remaining stump of the right atrial appendage in dogs $1 / 105$ and $11 / 98$. There were convincing signs of cerebral oedema in dog 15/108. The cerebral gyri were flattened and the cerebral sulci and lateral ventricles were severely compressed.

The only neurological sign of abnormality in the postoperative period was lethargy which occurred in $\operatorname{dog} 13 / 144$.

Brain damage No cell damage was found in the brains of the five dogs that were perfuse-fixed as controls (Figs 2 and 4). In the brains of experimental animals, nerve cell changes were of two types-diffuse and focal. Where nerve cells undergoing pathological changes were randomly distributed over a wide area with no clearly demarcated lesion, they were categorized as diffuse nerve cell changes. Focal lesions were small and well defined. They were either oval or wedge-shaped, and the widest dimension of the lesion never exceeded $4.0 \mathrm{~mm}$. Diffuse nerve cell changes were further classified as ischaemic cell change (Fig. 3) and acute cell swelling (Fig. 5). Only dubious signs of microvacuolation were seen in the cerebral cortex of dog 15/108.

Ischaemic cell changes were found in the cerebral cortices of two animals (15/108 and 16/86) and in the cerebellar Purkinje cells of one animal (14/119). All three of these animals had received non-pu'satile perfusions and the brains had been perfuse-fixed prematurely because of poor prognoses ('terminated experiments'). Two of these dogs $(14 / 119$ and 15/108) and one of the one-week survivors $(11 / 98)$ had developed acute cell swelling of the cerebellar Purkinje cells. Dog 15/108 also had some acute cell swelling of the pyramidal nerve cells of the parietal and temporal lobes. All four of the dogs with acute cell swelling had received non-pulsatile perfusions.

Generalized cell reactions were present in the form of laminar astrogliosis in layer 1 of the cerebral cortex of dog 14/119, and scattered intravascular and perivascular aggregations of lymphocytes and polymorphs in dog $12 / 117$. Both of these animals had received non-pulsatile perfusions.

Seven of the eight brains had small focal lesions varying in the stage of development from staining pallor and rarefaction of the neuropil (Fig. 6) to frank infarct in which all of the nerve cells had been replaced by lipid phagocytes, fibroblasts, and swollen astrocytes (Fig. 7). The locations of focal lesions are shown in Figures 8 and 9. An organiz- ing thrombus was found in a leptomeningeal artery close to the lesion shown in Figure 7. An organizing thrombus was found in a similar location in the brain of dog $13 / 144$, but no cerebral lesion was associated with this thrombus.

Other organ damage The examination of tissue sections obtained from organs other than the brain was not rewarding. However, pulmonary alveolar haemorrhages and marked pulmonary venous congestion were found in all animals. Cellular repair reactions were seen at the sites of incision in the heart. No cell damage was seen in the liver, jejunum or kidney of any animal.

\section{DISCUSSION}

Factors that have been considered to be responsible for diffuse or scattered nerve cell changes during extracorporeal circulation include anoxia (Javid et al., 1969), reduced cerebral blood flow (Brierley, 1963; 1967), hypoxaemia, and carbon dioxide poisoning (Björk and Hultquist, 1960). Non-pulsatile blood flow has only recently been considered as a possible cause of diffuse nerve cell changes (Sanderson et al., 1972a).

The mechanisms by which arterial pulsations improve tissue viability are as follows: $(a)$ interstitial fluid movement and the rates of formation and flow of lymph (and possibly cerebrospinal fluid) are increased (McMaster and Parsons, 1938; Parsons and McMaster, 1938); (b) the 'energy equivalent pressure' of pulsatile blood flow is higher than that of non-pulsatile blood flow at equal mean blood pressures (Shepard, Simpson, and Sharp, 1966); (c) the rate of tissue metabolism is higher during pulsatile than during non-pulsatile perfusion (Nonoyama, 1960: Ida, 1962 ; Shepard and Kirklin, 1969; Trinkle, Helton, Wood, and Bryant, 1969) presumably due partly to disturbance of the diffusion shells of substances involved in metabolism ; and $(d)$ it has been postulated that, since some blood flow will occur at end-systole, the 'critical closing pressure' (Burton, 1954) of arterioles may be lower for pulsatile than for non-pulsatile blood flow (Sanderson et al., 1972a).

These factors may be responsible for the diffuse nerve cell changes found in dog brains immediately and shortly after non-pulsatile perfusion. Oncotic pressure changes in the tissue fluids are thought to be intimately involved in the development of the nerve cell changes (Wright, 1972). The low incidence of diffuse nerve cell changes in the recovery group of animals suggests that the changes are not produced by one 


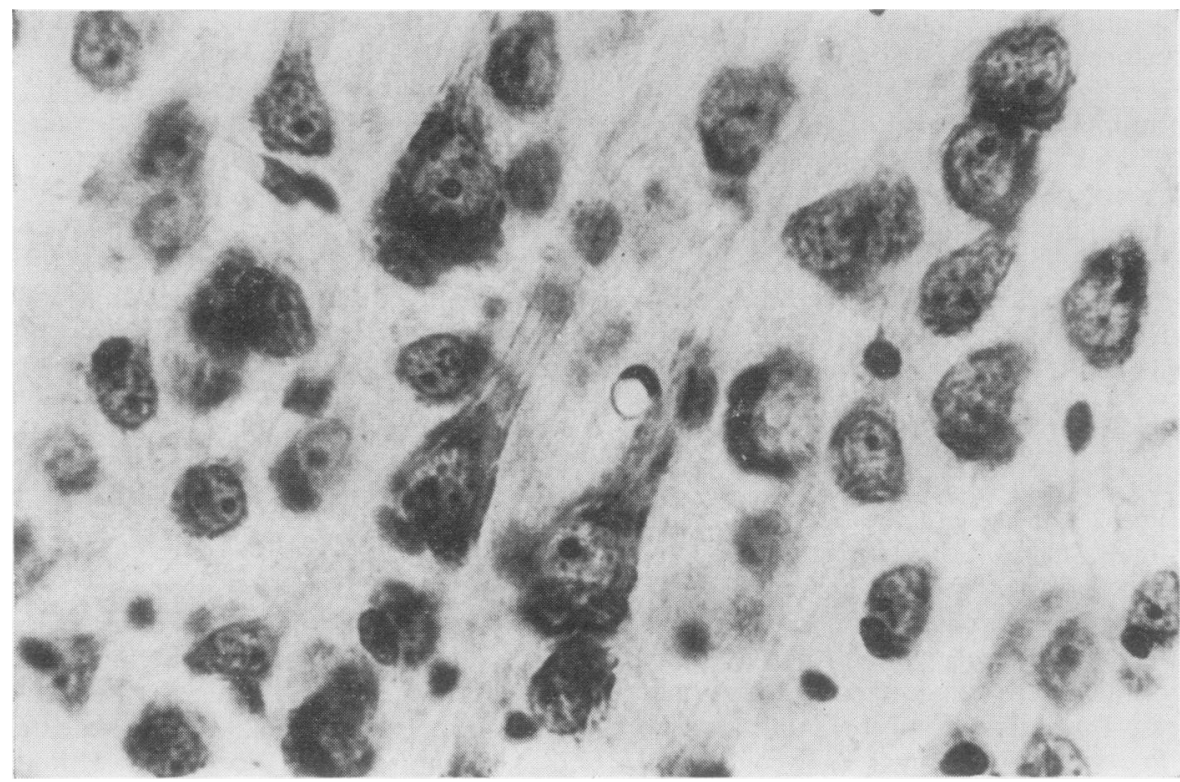

FIG. 2. Normal nerve cells in dog cerebral cortex. $L F B-C F V \times 700$.

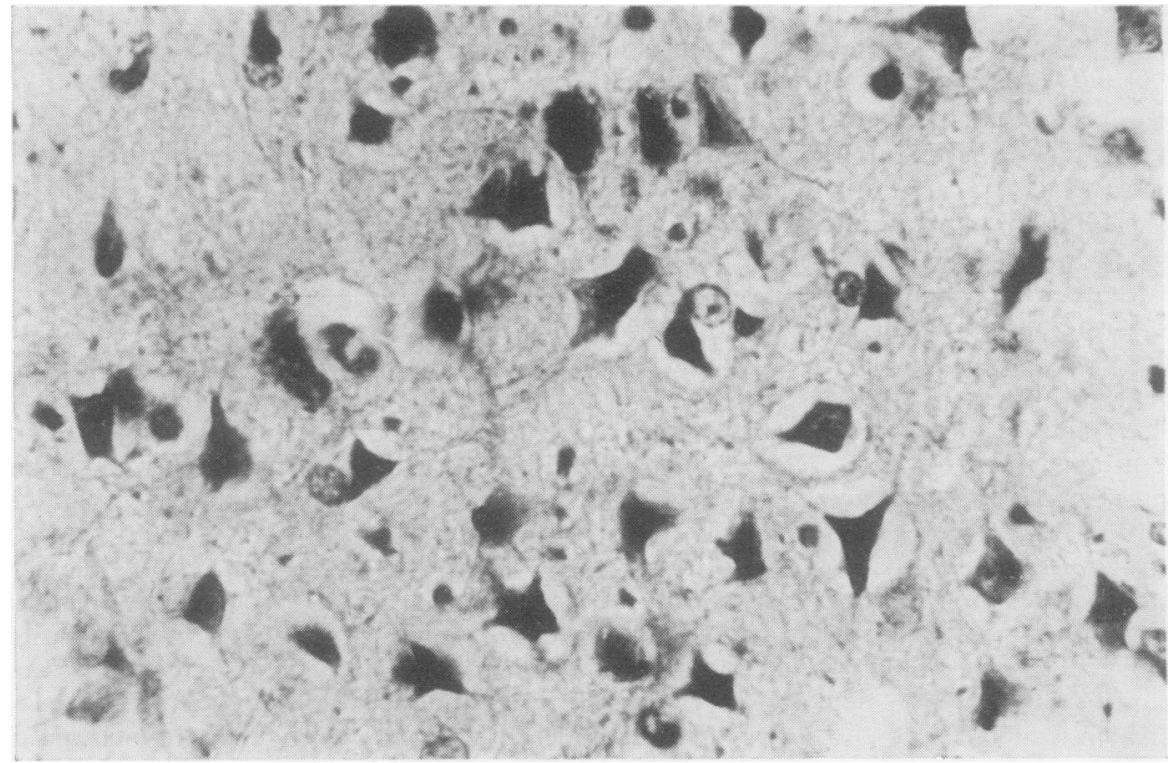

FIG. 3. Ischaemic cell change in dog cerebral cortex following non-pulsatile extracorporeal circulation and $7 \cdot 5$ hours recovery. $L F B-C F V \times 700$. 


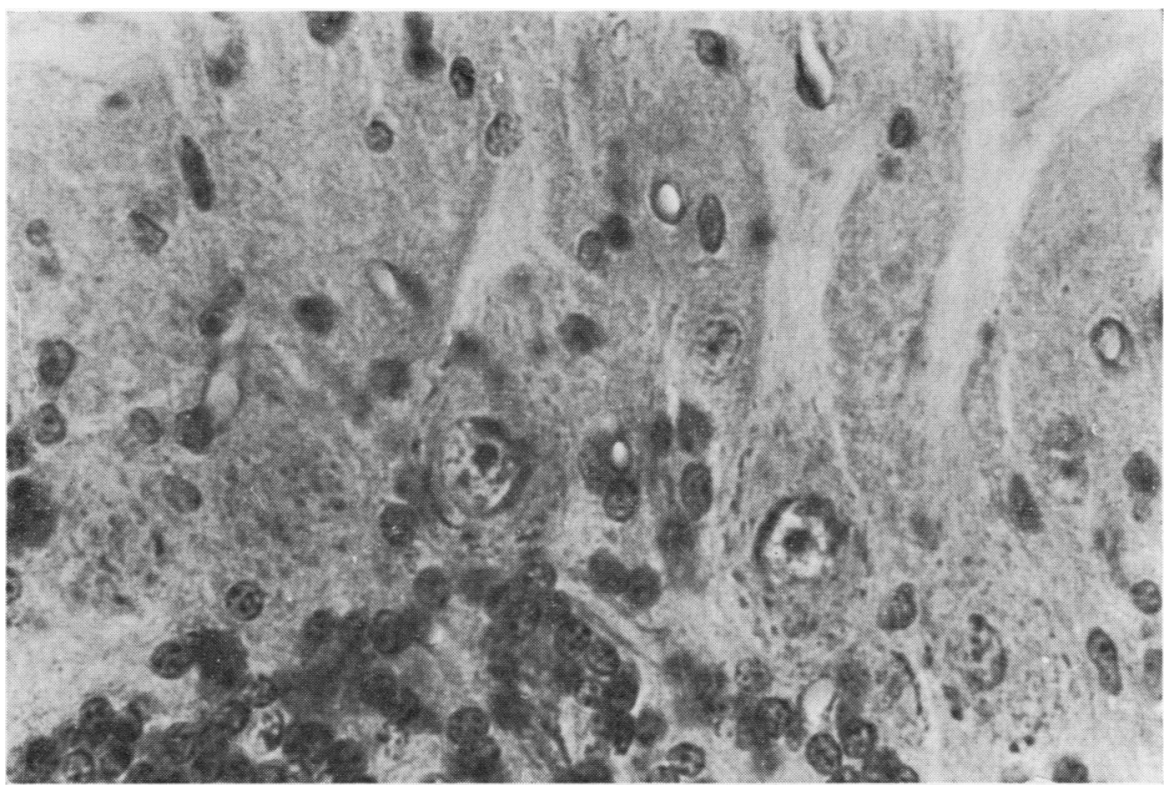

FIG. 4. Normal nerve cells in dog cerebellar cortex. H-PAS $\times 700$.

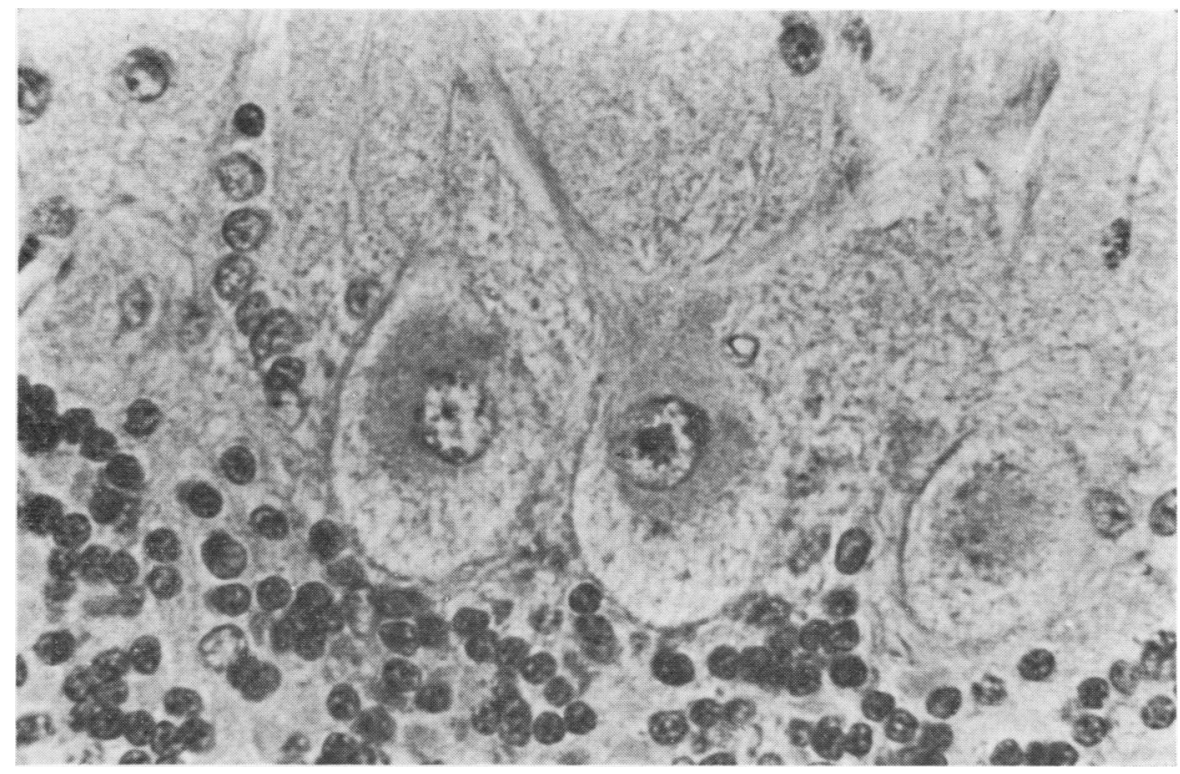

FIG. 5. Acute cell swelling of Purkinje cells in dog cerebellar cortex following nonpulsatile extracorporeal circulation and 3 hours recovery. $H-P A S \times 700$. 


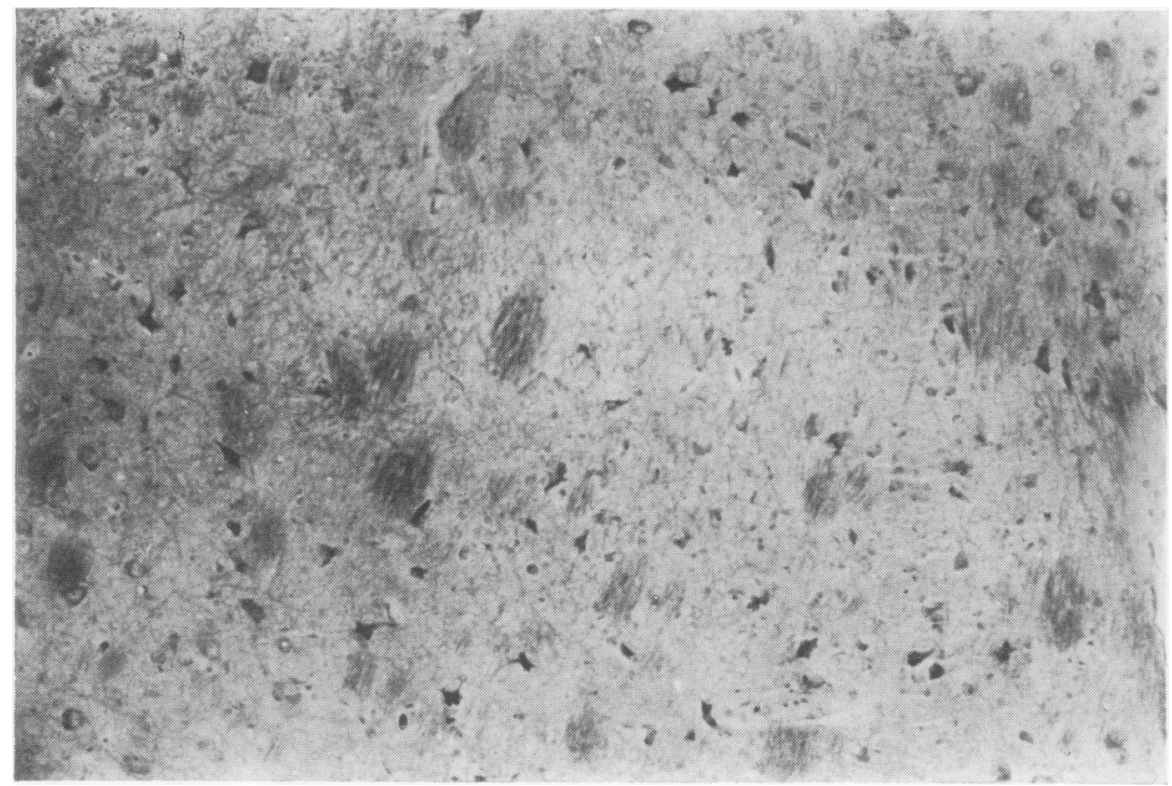

FIG. 6. Focal staining pallor in dog thalamus following extracorporeal circulation and 8 hours recovery. $L F B-C F V \times 140$.

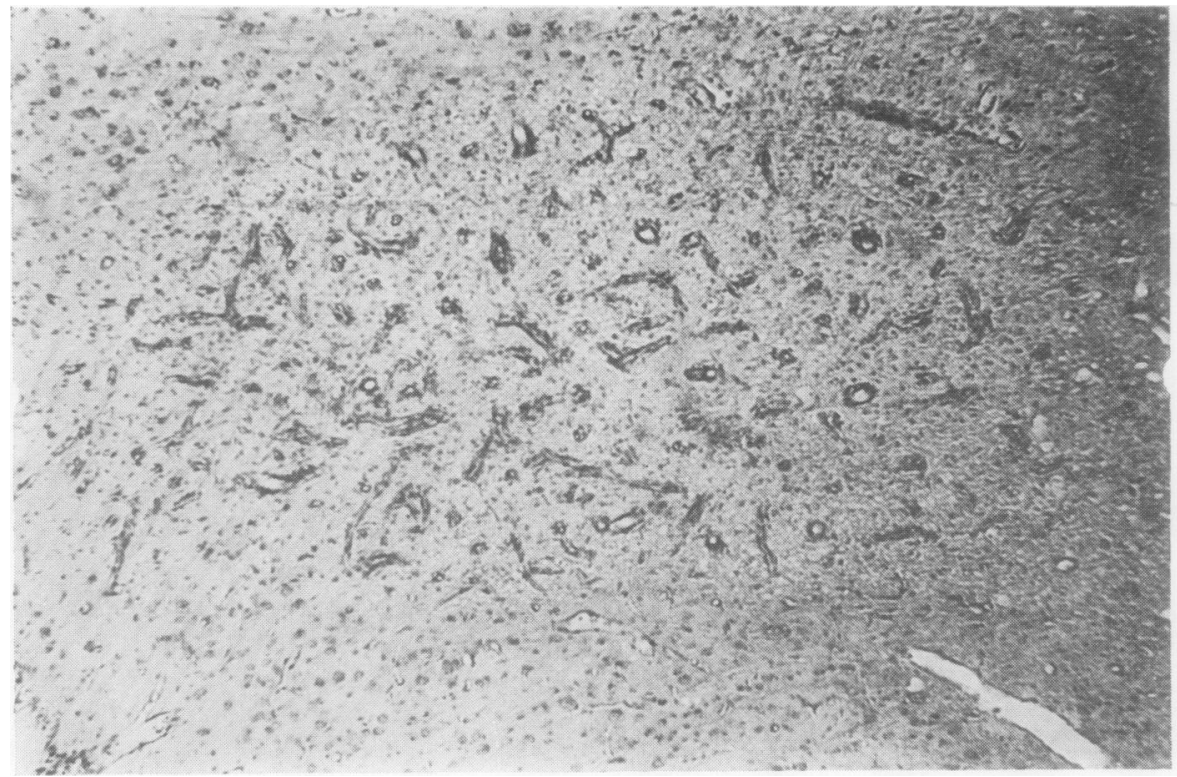

FIG. 7. Focal infarct in dog cerebral cortex following extracorporeal circulation and 7 days recovery. $L F B-C F V \times 140$. 


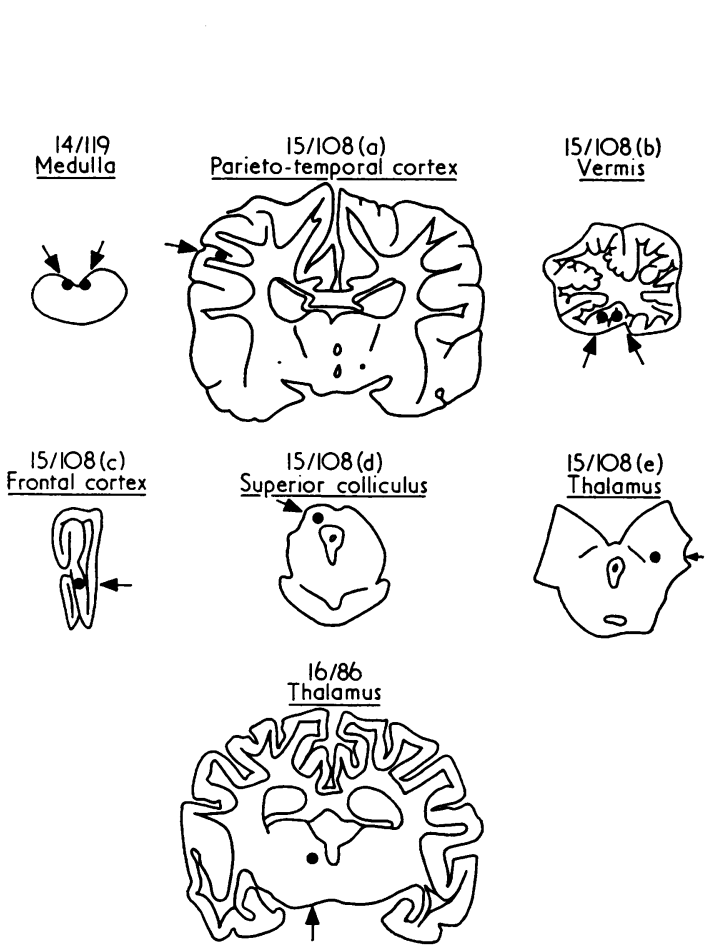

FIG. 8. Location of focal lesions in dog brains following extracorporeal circulation and 3-8 hours recovery. Numbers denote experiment number (Table I).

hour of non-pulsatile perfusion, or that they are reversible within the first postoperative week when the cardiac output is adequate. The latter condition may not be satisfied in human open-heart surgery patients, so that diffuse nerve cell changes may persist. It is probable that postoperative complications contributed to the development of diffuse nerve cell changes in the three animals whose recovery was terminated prematurely.

Focal lesions found in the brain following extracorporeal circulation have been considered to be due to cerebrovascular emboli of air (Arfel et al., 1967 ; Fishman, Carlsson, and Roe, 1969), silicone (Bleifeld, 1961 ; Ehrenhaft, Claman, Layton, and Zimmerman, 1961; Lindberg, Lucas, Sheagren, and Malm, 1961; Thomassen, Howbert, Winn, and Thompson, 1961), fat (Owens et al., 1958 ; Miller, Fonkalsrud, Latta, and Maloney, 1962 ; Caguin and Carter, 1963 ; Evans and Wellington, 1964 ; Hill et al., 1969 ; Danielson, Dubilier, and Bryant, 1970), platelet aggregates (Björk and Hultquist, 1960), and fibrin (Hill et al., 1969). Opinions have been supported by experi-
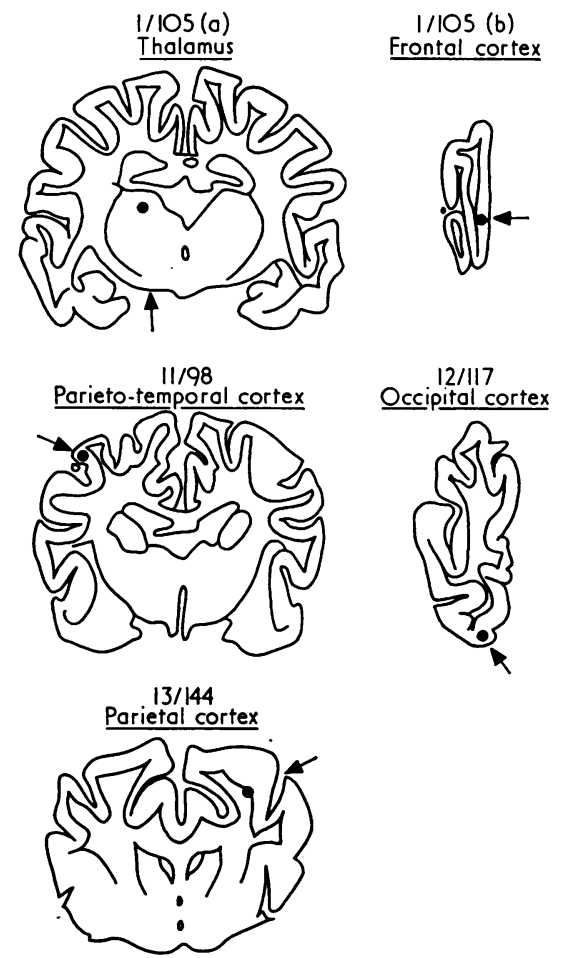

FIG. 9. Location of focal lesions in dog brains following extracorporeal circulation and 7 days recovery. Numbers denote experiment number (Table I).

mental work in which the emboli have been identified (Jordan, Tolstedt, and Beretta, 1958 ; Willman, Zafirocopoulos, and Hanlon, 1958 ; Adams et al., 1959 ; Smith, 1960 ; Lee et al., 1961 ; Swank and Porter, 1963 ; Wright, Sarkozy, Dobell, and Murphy, 1963 ; Spencer, Rossi, Yu, and Koepke, 1965; Selman, McAlpine, and Ratan, 1967 ; Aronstam, Greiger, Morris and Rigby, 1968 ; Ashmore, Svitek, and Ambrose, 1968 ; Bass and Longmore, 1969 ; Patterson and Kessler, 1969 ; Danielson et al., 1970).

In contrast to the restriction of diffuse nerve cell changes to the non-pulsatile groups of dogs, no differences were noticed in the incidences of focal lesions found in the brains of dogs subjected to pulsatile and non-pulsatile blood flows. Other experiments performed in our laboratory indicate that focal lesions may be due to circulatory emboli of gas microbubbles and blood cell aggregates. Further investigations are being conducted in an attempt to identify and eliminate the factors responsible for the formation of emboli.

It is possible that reversible diffuse nerve cell 
changes are at least partly responsible for the transient neurological sequelae to open-heart operations, while a combination of persistent diffuse nerve cell changes and focal lesions is responsible for some of the permanent neurological deficits. If this is correct, the replacement of roller pumps by pulsatile pumps in extracorporeal circuits should make a significant improvement to the postoperative neurological states of open-heart surgery patients.

The repeated occurrence of brain and lung damage in our experiments strongly suggests that these are important factors in determining the rate of mortality following extracorporeal circulation in dogs. The observation that the majority of animals that failed to recover consciousness had received non-pulsatile perfusions invites the conclusion that inadequate brain tissue perfusion was a primary cause of death.

The high rate of mortality in the pulsatile series was disappointing but not necessarily a condemnation of pulsatile blood flow because four of the eight deaths resulted from new technical problems. We have learned that the positioning of the aortic cannula for pulsatile perfusion is critical and that an excessively rapid upstroke on the pulmonary artery blood pressure waveform causes lung damage. This knowledge may lead to an improvement in the rate of survival in future experiments.

It is a pleasure to acknowledge the assistance of our colleagues in the W. E. Dunn Unit of Cardiology and the cardiac surgery team of the North Staffordshire Royal Infirmary, and to thank Professor W. T. Smith of the Neuropathology Department at the University of Birmingham Medical School for valuable help. The pulsatile pump was constructed by Messrs. P. Morton and G. Salway of GEC Power Engineering Ltd., and extensively rebuilt in the Keele University Workshops under the supervision of Mr. H. Wardell. Professor A. R. Gemmell provided the facilities of the Biology Department. One of us (J.M.S.) was in receipt of a research grant from the Birmingham Regional Hospital Board.

\section{REFERENCES}

Adams, J. E., Owens, G., Mann, G., Headrick, J. R., Munoz, A., and Scott, H. W. (1959). Experimental evaluation of Pluronic F-68 (a non-ionic detergent) as a method of diminishing systemic fat emboli resulting from prolonged cardiopulmonary bypass. Surg. Forum, $10,585$.

Arfel, G., Casanova, C., Naquet, R., Passelecq, J., and Dubost, C. (1967). Étude électro-clinique de l'embolie gazeuse cérébrale en chirurgie cardiaque. Electroenceph. clin. Neurophysiol., 23, 101.
Aronstam, E. M., Geiger, J. P., Morris, J. A., and Rigby, P. T. (1968). Preliminary observations on the performance of the Bramson membrane lung oxygenator. Ann thorac. Surg., 5, 367.

Ashmore, P. G., Svitek, V., and Ambrose, P. (1968). The incidence and effects of particulate aggregation and microembolism in pump-oxygenator systems. $J$. thorac. cardiovasc. Surg., 55, 691.

Bass, R. M., and Longmore, D. B. (1969). Cerebral damage during open heart surgery. Nature (Lond.), 222, 30.

Björk, V. O., and Hultquist, G. (1960). Brain damage in children after deep hypothermia for open-heart surgery. Thorax, 15, 284.

Bleifeld, W. (1961). Cerebrale "Fett" Embolie nach Operationen mit der Herz-Lungen-Maschine. Thoraxchirurgie, 9, 12.

Brierley, J. B. (1963). Neuropathological findings in patients dying after open-heart surgery. Thorax, 18, 291.

- (1967). Brain damage complicating open-heart surgery A neuropathological study of 46 patients. Proc. roy. Soc. Med., 60, 858.

Burton, A. C. (1954). Relation of structure to function of the tissues of the wall of blood vessels. Physiol. Rev., 34, 619.

Caguin, F., and Carter, M. G. (1963). Fat embolism with cardiotomy with the use of cardiopulmonary bypass. J. thorac. cardiovasc. Surg., 46, 665.

Danielson, G. K., Dubilier, L. D., and Bryant, L. R. (1970). Use of Pluronic F-68 to diminish fat emboli and haemolysis during cardiopulmonary bypass. J. thorac. cardiovasc. Surg., 59, 178.

DeBakey, M. (1934). Simple continuous-flow blood transfusion instrument. New Orleans med. surg. J., 87, 386.

Drew, C. E. (1961). Profound hypothermia in cardiac surgery. Brit. med. Bull., 17, 37.

Ehrenhaft, J. L., Claman, M. A., Layton, J M., and Zimmerman, G. R. (1961). Cerebral complications of openheart surgery: Further observations. J. thorac. cardiovasc. Surg., 42, 514.

Evans, E. A., and Wellington, J. S. (1964). Emboli associated with cardiopulmonary bypass. $J$. thorac. cardiovasc. Surg., 48, 323.

Fishman, N. H., Carlsson, E., and Roe, B. B. (1969). The importance of the pulmonary veins in systemic air embolism following open-heart surgery. Surgery, 66, 655.

Hill, J. D., Aguilar, M. J., Baranco, A., de Lanerolle, P., and Gerbode, F. (1969). Neuropathological manifestations of cardiac surgery. Ann. thorac. Surg., 7, 409.

Hurt, R., Perkins, H. A., Osborn, J. J., and Gerbode, F. (1956). The neutralization of heparin by protamine in extracorporeal circulation. J. thorac. cardiovasc. Surg., 32, 612 .

Ida, Y. (1962). Experimental studies on carbohydrate metabolism during heart lung bypass, with special reference to a comparison of pulsatile flow with non-pulsatile flow. Arch. Jap. Chirurgie, 31, 181.

Javid, H., Tufo, H. M., Najafi, H., Dye, W. S., Hunter, J. A., and Julian, O. C. (1969). Neurological abnormalities following open-heart surgery. $J$. thorac. cardiovasc. Surg., 58, 502.

Jordan, P., Tolstedt, G. E., and Beretta, F. F. (1958). Microbubble formation in artificial oxygenation. Surgery, 43, 266. 
Lee, W. H., Krumhaar, D., Fonkalsrud, E. W., Schjeide, O. A., and Maloney, J. V. (1961). Denaturation of plasma proteins as a cause of morbidity and death after intracardiac operations. Surgery, 50, 29.

Lindberg, D. A. B., Lucas, F. V., Sheagren, J., and Malm, J. R. (1961). Silicone embolization during clinical and experimental heart surgery employing a bubble oxygenator. Amer. J. Path., 39, 129.

McMaster, P. D., and Parsons, R. J. (1938). The effect of the pulse on the spread of substances through tissues. J. exp. Med., 68, 377.

Miller, J. A., Fonkalsrud, E. W., Latta, H. L., and Maloney, J. V. (1962). Fat embolism associated with extracorporeal circulation and blood transfusion. Surgery, 51, 448.

Nonoyama, A. (1960). Haemodynamic studies on extracorporeal circulation with pulsatile and non-pulsatile blood flows. Arch. Jap. Chirurgie, 29, 1381.

Owens, G., Adams, J. E., Dawson, R. E., Lance, E. M., Sawyers, J. L., and Scott, H. W. (1958). Observed central nervous system responses during experimental employment of various pump-oxygenators. Surgery, 44, 240.

Parsons, R. J., and McMaster, P. D. (1938). The effect of the pulse upon the formation and flow of lymph. J. exp. Med., 68, 353.

Patterson, R. H., and Kessler, J. (1969). Microemboli during cardiopulmonary bypass detected by ultrasound. Surg. Gynec. Obstet., 129, 505.

Sanderson, J. M., Morton, P. G., Tolloczko, T., Vennart, T., and Wright, G. (1972a). The Morton-Keele pump: A new hydraulically activated pulsatile pump for use in extracorporeal circulation. Med. Biol. Eng., in press.

—, Wright, G., and Sims, F. W. (1972b). Brain damage in dogs immediately following pulsatile and non-pulsatile blood flows in extracorporeal circulation. Thorax, 27, 275.

Selman, M. W., McAlpine, W. A., and Ratan, R. S. (1967). The effectiveness of various heart-lung machines in the elimination of microbubbles from the circulation. $J$. thorac. cardiovasc. Surg., 53, 613.
Shepard, R. B., and Kirklin, J. W. (1969). Relation of pulsatile flow to oxygen consumption and other variables during cardiopulmonary bypass. $J$. thorac. cardiovasc. Surg., 58, 694.

—- Simpson, D. C., and Sharp, J. F. (1966). Energy equivalent pressure. Arch. Surg., 93, 730.

Smith, W. T. (1960). Cerebral lesions due to emboli of silicone anti-foam in dogs subjected to cardiopulmonary bypass. J. Path. Bact., 80, 9.

Spencer, F. C., Rossi, N. P., Yu, S-C., and Koepke, J. A. (1965). The significance of air embolism during cardiopulmonary bypass. J. thorac. cardiovasc. Surg., 49, 615.

Swank, R. L., and Porter, G. A. (1963). Disappearance of micro-emboli transfused into patients during cardiopulmonary bypass. Transfusion, 3, 192.

Thomassen, R. W., Howbert, J. P., Winn, D. F., and Thompson, S. W. (1961). The occurrence and characterization of emboli associated with the use of a silicone antifoaming agent. J. thorac. cardiovasc. Surg., 41, 611.

Trinkle, J. K., Helton, N. E., Wood, R. E., and Bryant, L. R. (1969). Metabolic comparison of a new pulsatile pump and a roller pump for cardiopulmonary bypass. $J$. thorac. cardiovasc. Surg., 58, 562.

Willman, V. L., Zafiracopoulos, P., and Hanlon, C. R. (1958). Air embolism. In: Extracorporeal Circulation, edited by J. G. Allen, pp. 295-302. Thomas, Springfield, Illinois.

Wright, E. S., Sarkozy, E., Dobell, A. R. C., and Murphy, D. R. (1963). Fat globulemia in extracorporeal circulation. Surgery, 53, 500.

Wright, G. (1972). Ultrastructural changes in dog brain immediately following prolonged anaesthesia and nonpulsatile blood flow in extracorporeal circulation. Brit. $J$. exp. Path., 53, in press.

and Sanderson, J. M. (1970). Improved method for fixation of dog brain by vascular perfusion. J. Path. Bact., 100, 295. 